\title{
"Don't worry my good man-you won't understand our medical talk"': consent to treatment today
}

Patient: " Do you really think this operation will make me see better, doctor?"

Doctor " Oh yes - it is a very good operation with a $98 \%$ success rate!"

Patient "Oh good! What does that mean doctor?"

Doctor: "Well ... er . . .How long have you got? . . And how much do you really want to know? ..."

"When $I$ use a word," Humpty Dumpty said in a rather scornful tone, "it means just what I choose it to mean, neither more nor less". (Alice Through The Looking Glass, Lewis Carroll)

It wasn't very long ago that, to the vast majority of ophthalmologists, "consent" implied a brief discussion about a proposed procedure and the signing of a form by the doctor and the patient. How the world has changed! Today the issue of consent is highly topical: daily, articles in the national press raise issues considered irrelevant perhaps only five years ago. Litigation, commonplace for the American practitioner, is in the United Kingdom rapidly being seen as an inevitable consequence of medical practice. Doctors are often shocked to discover that legal actions can not only be brought for "Malpractice" or "Negligence" but also where the doctor has carried out the procedure well but has failed to warn of a small risk that in fact occurs.

\section{How much information should a doctor give?}

Times have changed indeed. Take for example the 1954 case of Hatcher $v$ Black. ${ }^{2}$ Here, a BBC broadcaster went to Bart's suffering from a toxic thyroid gland for which an operation was recommended. She asked if it posed any risks to her voice and was reassured. However, as a result of damage to a nerve during the operation she could no longer speak properly. The distinguished Lord Justice Denning stated;

"What should the doctor tell his patient? $\mathrm{Mr}$ Tuckwell admitted that on the evening before the operation he told the plaintiff that there was no risk to her voice, when he knew that there was some slight risk, but that he did it for her own good because it was of vital importance that she should not worry. In short he told a lie, but he did it because he thought in the circumstances it was justifiable."

The court went on to hold that the doctor had been reasonable not to warn the patient, given that "he had done what a wise and good doctor so placed would do." This attitude is derived from the teachings of Hippocrates, nearly 2500 years ago. “ . . . Perform your medical duties calmly and adroitly, concealing most things from the patient while you are attending to him. Give necessary orders with cheerfulness and sincerity turning his attention away from what is being done to him; sometimes reprove sharply and sometimes comfort with solicitude and attention-revealing nothing of the patient's future or present condition- - for many patients through this course have taken a turn for the worse."
Courts overseas have, however, taken a more robust stance on the rights of patients, as the Australian case of Rogers $v$ Whittaker $^{3}$ demonstrates. In this case a woman went to an ophthalmologist because of difficulty with reading. She was presbyopic and glasses were prescribed. The ophthalmologist noted in addition that her right eye was almost totally blind as a result of a childhood penetrating injury. She said she had been advised against surgery in the past. The ophthalmologist indicated that modern surgery offered her the chance to improve its vision and referred her to a colleague. The patient had repeatedly expressed worry about the risk to her "good" eye of this operation to her "bad" eye, even though she had not specifically asked about the condition that eventually occurred. The consensus of experts at the trial was that the procedure in question carried approximately a 1 in 14000 risk of sympathetic ophthalmia. Of this small risk the surgeon chose not to inform his patient.

She had the surgery. Sympathetic ophthalmia occurred. In spite of all treatment she became blind in both eyes. At no time was it alleged that the surgeon had carried out the operation negligently. The allegation made was that the patient had not been given sufficient information to give an informed consent.

The Australian judge found in her favour. In his judgment he reminded the court that if a complication of an operation was extremely rare and even if it is a threat to function, the surgeon need not necessarily draw attention to it. However, if the patient was sufficiently concerned to ask a direct question such as about the risk to the sight of the other eye the surgeon has a responsibility to answer the question truthfully and directly no matter how rare the risk.

The case was contested to the highest level and in every case the court found in favour of the patient. The majority of the High Court (the highest court in Australia) held:

\begin{abstract}
"The respondent may not have asked the right question, yet she was credited as having made clear her great concern that no injury should befall her one good eye. In which case it could be argued that the risk though small was material to her decision; in the sense that a reasonable person in the patient's position would be likely to attach significance to the answer in respect to the risk and thus required a warning."
\end{abstract}

\section{The position in England today}

English courts have been slower to recognise the duties of doctors towards their patients than their American and Commonwealth cousins. However, the tide is turning and English courts are beginning to make moves to uphold a patient's right to information. Today under English law a doctor is under a clear legal obligation to tell the truth if asked a direct question, ${ }^{4}$ and should warn a patient of anything that poses "a substantial risk of grave adverse consequences" (such as a $10 \%$ risk of a stroke ${ }^{6}$ ) or one that is a "significant risk that would affect the decision of a reasonable patient."7 
"I am of the opinion that the judge might in certain circumstances come to the conclusion that disclosure of a particular risk was so obviously necessary to an informed choice on the part of the patient that no reasonably prudent medical man would fail to make it. The kind of case I have in mind would be an operation involving a substantial risk of grave adverse consequences, as for example, the $10 \%$ risk of a stroke from the operation that was the subject of the Canadian case of Riebl $v$ Hughes (1980) 114 DLR (3d). In such a case, in the absence of some cogent clinical reason why the patient should be informed, a doctor, recognising and respecting his patient's right of decision, could hardly fail to appreciate the necessity for an appropriate warning" (per Lord Bridge in Sidaway [1985] 1 AC 871at 900, as cited by Lord Woolf in Pearce)

The question for the ophthalmologist to determine is what level of risk a "reasonable patient" would consider significant!

Arguably and most significantly for the ophthalmologist, a patient who is considering elective surgery cannot be fully informed unless he or she knows of all possible risks and their likelihood.

For the patient, the questions to ask may or may not be obvious - what he or she wants to know at the end of the day is "What might go wrong for me?"

The problems for the practitioner do not end here though! Until recently a doctor could not be considered negligent if he acted in accordance with the faithful mantra of "the responsible body of medical opinion" (the Bolam test ${ }^{8}$ ). Today this is not enough. Any decision taken by a doctor must stand up to "logical analysis" (the "new Bolam" or Bolitho test). Referring to this new standard Lord Woolf (the most senior judge in the case of Pearce above) commented in a recent speech "until recently the courts treated the medical profession with excessive deference, but recently the position has changed." 9

In England legally a doctor does not have to provide information tailored to the particular patient, although realistically this is what good practice requires. This is where the law and ethics diverge: GMC guidelines ${ }^{10}$ emphasise the importance for both patient and doctor of ensuring that the patient has been given sufficient information to make a decision that is appropriate and correct for him or her. It is therefore vital for the practitioner to make sure that he is aware of what that particular patient might consider relevant to his or her own decision.

\section{What are the real reasons for obtaining a patient's consent?}

Today most doctors would agree that each competent individual has a right to self determination-which includes the right to decide what will happen to his or her own body. In the British Medical Association's view it is this respect for others and their rights that lies at the heart of the issue of consent and must be a major part of any relationship between doctor and patient.

This basic right is protected in law and means that (except in the case of an emergency) to touch a patient without his or her consent is an assault. Taken one step further, a patient must have sufficient information to be able to make an informed choice whether to have the recommended treatment or not. It is information that gives control, control for the doctor to decide for the patient and control for the patient to decide for himself. It is now accepted that a competent individual may go as far as to refuse all treatment even if as a result he may die. ${ }^{11}$
Clinically it is also obvious that the doctor/patient relationship is one based on trust. As such a doctor has a duty to act in his patient's best interest and thus to try to recognise what the patient really wants. It is only rarely that patients want the doctor to make the choice for them and it is clear that most patients can choose better for themselves than doctors can choose for them. ${ }^{12}$ Health is only one value among many that an individual may have. What intervention if any best suits the particular patient depends on that person's values and cannot be second guessed by a doctor. Furthermore, studies ${ }^{13}$ have shown that patients fare much better when they feel in control of their own treatment, acting in partnership with their doctor. Increasingly, in the 21 st century a "broad picture" approach is vital, to see the patient as an individual, in the context of his or her social and family background.

"If the doctor making a balanced judgment advises the patient to submit to the operation, the patient is entitled to reject that advice for reasons which are rational or irrational or for no reason. The duty of the doctor in these circumstances, subject to his overriding duty to have regard to the best interest of the patient, is to provide the patient with information which will enable the patient to make a balanced judgment. A patient may make an unbalanced judgment because he is deprived of adequate information. A patient may also make an unbalanced judgment if he is provided with too much information and is made aware of possibilities which he is not capable of assessing because of his lack of medical training, his prejudices or his personality" (per Lord Templeman in Sidaway [1985] 1AC 871 at 904, as cited by Lord Woolf in Pearce)

\section{The 21st century}

Traditionally our society has been based on the individual's duty to society. Today it is the concept of the "rights" of the individual that has moved to the forefront of our morality. Although it seems hard to believe, the language of human rights is only a recent innovation and was unheard of before the second world war (although the concept of "natural rights" dates from the great Greek thinkers). Nowadays it seems that the client or consumer is king. Most patients expect to be treated as an individual and many as a client. The fact that our society values the individuality and dignity of its members requires respect for people's autonomy.

The government has been quick to see that one of the failings of the current NHS has been the lack of patient recognition. The "NHS plan" draws on patient involvement, including the new "Patient advocate and liaison services" and "Patient's forum," and makes specific mention of the issue of consent, ${ }^{14}$ providing for an official "Review of consent."

\section{Practically speaking ... .}

How does a doctor give sufficient information to gain valid consent from the patient? The American doctor is urged (by "Dr Claimfree"!) to refer his patient to www. yoursurgery.com for a thorough information and consent service! Despite the obvious attraction, such a website won't provide a solution to all the ophthalmologist's problems. As a practising doctor it is vital to understand that it is the discussion with the patient that constitutes consent, not the signing of the form. All the form does is to provide evidence that a discussion has taken place and no more than that. ${ }^{15}$ If a patient signs a multi-paged form (sometimes graced with the term "protocol" it does not necessarily mean that the patient has understood a single 
word. Similarly, sufficient clearly understandable information is unlikely to be given by (albeit enthusiastic) SHOs thrusting consent forms in front of patients or their parents on the way into theatre. Consent is best documented in the patient record or in a letter, outlining the nature of the discussion held with the patient and suggesting that the patient is free to ask for further discussion if they do not feel that all has been made clear.

Not only is the discussion the main forum for the doctor to provide the patient with the necessary information, but also it is only by discussion that the doctor can, through listening to the individual patient, understand what is important and relevant to him. It is also the time when the ophthalmologist can ascertain whether the patient does in fact understand the implications of the proposed procedure or not. A patient's consent must be competent, informed, and voluntary (that is, freely given). It is therefore up to the doctor to ensure not only that the patient is competent to take the decision, ${ }^{16}$ but also that the patient does not feel under undue pressure from the doctor himself or from some family member (or even from an insurance company). It is also clear that a patient in pain or very frightened will be less likely to take on board information than one who has the chance to go home and think about the options in their own time. Consent is therefore an ongoing matter and one that must be regularly reviewed as treatment progresses and changes.

\section{"You decide for me, doctor"}

Every doctor will have treated a patient who clearly wants the doctor to take the decision for him (until that is anything goes wrong!). How should we best explain the necessity of an informed choice to such a reticent patient? This is obviously a matter for the individual ophthalmologist, but a prepared strategy for these situations is a start. The doctor has a duty to remind the patient that while he may hold the key to the medical knowledge, the patient is the only one who can make decisions about his own life, even if unwilling to do so. Whatever the outcome, documentation of the patient's decision must be clear.

\section{And the implications of all this?}

It is obvious that the duty to provide so much specific information has huge implications for consultants, NHS trusts and management. Consultants will have to be sure that correct, sufficient, and understandable information is given to patients in their care. Trusts will need to consider the effects on clinic times, waiting lists, and budgets. Consent requires time, energy and allocation of resources and is a vital part of a patient's quest to get well. Planners, managers, and budget holders must bite the bullet!

The crux of the issue and the holy grail of today's practice must be successfully to balance spending sufficient time with the patient to have an understanding of what is important to him or her with the constraints of NHS workload, waiting lists, and government targets.
Fundamentally, the dialogue necessary to achieve truly informed consent is more rewarding than time consuming. It improves trust between doctor and patient, it makes both feel more secure and, should complications arise, communication is already properly established and can be maintained.

"Formerly, when religion was strong and science weak, men mistook magic for medicine; now when science is strong and religion weak, men mistake medicine for magic." (Science and scientism, Thomas Szasz in The Second Sin.)

The authors thank James Badenoch, QC, and Professor Frank Billson for carefully reading the manuscript and for their very helpful comments.

BEA TEUTEN

solicitor

DAVID TAYLOR

ophthalmologist

\section{Further reading}

Silverman J, Kurtz S, Draper J. Skills for communicating with patients. London: Radcliffe Medical Press, 1998.

Somerville A. Medical ethics today: its practice and philosophy. London: BMJ Publishing Group.

Seeking patient's consent. London: General Medical Council.

Kennedy I. Treat me right - essays in medical law and ethics. Oxford: Clarendon Press, 1998.

Buchanan AE, Brock DW. Deciding for others-the ethics of surrogate decision making. Cambridge: Cambridge University Press, 1990.

1. Modified from Doctor in the House. By Richard Gordon. London: House of Status, 2001:56.

Hatcher $v$ Black (1954) Times, 2 July QBD.

2 Hatcher $v$ Black (1954) Times, 2 July QBD.

3 Rogers $v$ Whitaker (1992) 67 ALJR 47 Australian High Cour

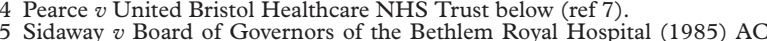
871 .

6 Sidaway (supra ref 4) quoting Reihl $v$ Hughes (1980) 114 DLR Canada

7 Pearce $v$ United Bristol Healthcare NHS Trust (1999) PIQR 53.

8 Bolam $v$ Friern Hospital Management Committee (1957) 1 WLR 582.

9 Provosts Lecture Series UCL 17.01.2001.

10 Seeking Patients' Consent Paragraph 6.

$11 \operatorname{Re} T$ (1992) 4 All ER 649 per Lord Donaldson "An adult patient who ... suffers from no mental incapacity has an absolute right to choose to whether to consent to medical treatment, to refuse it or to choose one rather that another of the treatments being offered .... The right of choice is not limited to decisions which others might regard as sensible. It exists notwithstanding that the reasons for making the choice are rational, irrational, unknown or even non-existent."

12 Amusingly the President's Commission for the Study of Ethical and Legal Problems in Medicine "Making Health Care Decisions" US Printing Office 1982 found that whilst $72 \%$ of the American public wanted their health 1982 found that whilst $72 \%$ of the American public wanted their health
care decisions to be joint with their doctors, $88 \%$ of doctors said that they believed that the public preferred then to take the decisions! Korsch et al believed that the public preferred then to take the decisions! Korsch et al
(1968) found that paediatricians' use of technical language (eg "oedema") and medical short hand (eg "history") was a barrier to communication in and medical short hand (eg "history") was a barrier to communication in
more than half of the 800 visits studied. Mothers were confused by the terms used by doctors but rarely asked for clarification of unfamiliar terms. (Pediatrics 42: 855-871)

13 Hall JA, Rotter DL, Katz NR. Metaanalysis of correlates of provider behaviour in medical encounters. Med Care 1988;28:675.

14 The NHS Plan, paragraph 10.22. London: Stationery Office.

15 Chatterton $v$ Gerson (1981) 1 All ER 257 at 265 per Bristow J: "I should add that getting the patient to sign a pro forma expressing consent to undergo the operation "the effect and nature of which have been explained to me", as was done here in each case, should be a valuable reminder to everyone of the need for explanation and consent. But it would be no defence to an action based on trespass to the person if no explanation had in fact been given. The consent would have been expressed in form only, not in reality."

16 s8 Family Law Reform Act 1969 provides that the consent of a minor to any surgical medical or dental treatment is as effective as it would be if over 18 . 